\title{
Bacteria-Responsive Biomimetic Selenium Nanosystem for Multidrug-Resistant Bacterial Infection Detection and Inhibition
}

Ange Lin ${ }^{a, \dagger}$, Yanan Liu ${ }^{a, b \dagger}$, Xufeng Zhu ${ }^{a}$, Xu Chen ${ }^{a}$, Jiawei Liu ${ }^{a}$, Yanhui Zhou ${ }^{a}$, Xiuying

Qin $^{a}$ and Jie Liu ${ }^{a *}$

${ }^{\text {a }}$ Department of Chemistry, Jinan University, Guangzhou 510632, China

${ }^{\mathrm{b}}$ College of Life Sciences, Shenzhen University, Shenzhen, Guangdong, 518060,

China

* Corresponding author E-mail addresses: tliuliu@jnu.edu.cn (Jie Liu)

Tel/Fax: +86-20-85220223

$\uparrow$ These authors contributed equally to the work. 


\section{METHODS}

Synthesis of $\Delta-\left[\mathbf{R u}(\mathbf{p h e n})_{2}(\mathbf{t i p})\right]\left(\mathbf{C l O}_{4}\right)_{2} \bullet 2 \mathbf{H}_{2} \mathrm{O} . \mathrm{RuCl}_{3} \bullet \mathrm{nH}_{2} \mathrm{O}(1.56 \mathrm{~g}, \sim 6 \mathrm{mmol})$, 1,10-Phenanthroline (phen) (1.92 g, $12 \mathrm{mmol}$ ), and lithium chloride (1.68 g, $28 \mathrm{mmol}$ ) were added to a three-necked flask, then $10 \mathrm{~mL}$ DMF was added, and heated under reflux for 8 hours with the protection of argon. After cooled to room temperature, acetone was added and frozen overnight. After suction filtration, the precipitate was washed with ice water and cold acetone for several times. Then after vacuum dried, the purple-black crystallites, cis- $\left[\mathrm{Ru}(\text { phen })_{2} \mathrm{Cl}_{2}\right] \cdot 2 \mathrm{H}_{2} \mathrm{O}$, was collected.

2.2 g cis- $\left[\mathrm{Ru}(\text { phen })_{2} \mathrm{Cl}_{2}\right] \cdot 2 \mathrm{H}_{2} \mathrm{O}, 23 \mathrm{~mL}$ pyridine (py) and $46 \mathrm{~mL}$ water were stirred under reflux with heating for. After evaporating all the solvent under reduced pressure, the obtained red solid was dissolved in methanol. Then added diethyl ether, and placed at room temperature to precipitate a large amount of red crystals. After filtered by suction and washed with ether for several times red crystals, cis$\left[\mathrm{Ru}(\text { phen })_{2}(\mathrm{py})_{2}\right] \mathrm{Cl}_{2}$, was obtained.

$1.95 \mathrm{~g}$ cis- $\left[\mathrm{Ru}(\mathrm{phen})_{2}(\mathrm{py})_{2}\right] \mathrm{Cl}_{2}$ was dissolved in $30 \mathrm{~mL}$ of water, and $0.5 \mathrm{M}$ $O, O^{\prime}$-dibenzoyl-D-tartrate sodium solution was added with stirring at room temperature. After stirring for 10 minutes, the solution was placed in a fume hood, and a large amount of red crystal, $\Delta$-[Ru(phen $\left.)_{2}(\text { py })_{2}\right]\left[O, O^{\prime}\right.$-dibenzoyl-D-tartrate $] \cdot 12 \mathrm{H}_{2} \mathrm{O}$, were obtained after a week. $\Delta$-[Ru(phen $\left.)_{2}(\mathrm{py})_{2}\right]\left[O, O^{\prime}\right.$-dibenzoyl-d-tartrate $] \cdot 12 \mathrm{H}_{2} \mathrm{O}(0.26 \mathrm{~g}, 0.2 \mathrm{mmol})$, tip (2-Thiophenimidazo[4,5-f][1,10]phenanthroline) $(0.18 \mathrm{mg}, 0.56 \mathrm{mmol})$, were mixed with ethylene glycol and water, refluxed at $120{ }^{\circ} \mathrm{C}$ for 6 hours. After cooled to room 
temperature, diluted with water, filtered to remove unreacted ligand, the dark red filtrate was obtained. A saturated sodium perchlorate solution was added to the filtrate to obtain a large amount of orange-yellow precipitate for removing impurities. After suction filtration, the precipitate was washed several times with water and diethyl ether, and vacuum dried to obtain an orange-red crude product. The dried crude product was dissolved in a small amount of acetonitrile and passed through a neutral alumina column. The main red component was rinsed with acetonitrile and methylbenzene $(2: 1, \mathrm{~V} / \mathrm{V})$ mixed solvent, dried under reduced pressure, and recrystallized to obtain the red crystal, $\Delta-\left[\mathrm{Ru}(\mathrm{phen})_{2}(\mathrm{tip})\right]\left(\mathrm{ClO}_{4}\right)_{2} \cdot 2 \mathrm{H}_{2} \mathrm{O}$.

The drug loading and encapsulation efficiency calculation. In order to detect the drug loading and encapsulation efficiency, the concentration of Ru-Se NPs in the supernatant was determined by centrifugation and using an ultraviolet-visible spectrophotometer. The standard curve of Ru-Se NPs is drawn by dissolving Ru-Se NPs in PBS (0.01 M, pH 7.4) and scanning at a wavelength of 200-700 nm. The maximum absorption wavelength of Ru-Se NPs is $220 \mathrm{~nm}$. Accurately absorb standard solutions 5.0, 10.0, 20.0, 30.0, 40.0, $50.0 \mu \mathrm{g} / \mathrm{mL}$, and measure the change in absorption intensity at $220 \mathrm{~nm}$ with the concentration $\mathrm{C}(\mu \mathrm{g} / \mathrm{mL})$ as the abscissa and the absorbance A as the ordinate as the standard curve. Subsequently, the drug loading rate of the prepared Ru-Se@G NPs was measured, and the Ru-Se@G NPs lyophilized powder was taken out and reconstituted, and the supernatant was obtained by ultracentrifugation. The absorbance A value was measured at a wavelength of $220 \mathrm{~nm}$, and the amount of free Ru-Se NPs was obtained according to the standard curve 
equation, and the drug loading (DL) and encapsulation efficiency (ER) of the Ru-Se@G NPs nanosystem were calculated.

Surface area calculation of RBC membrane and Ru-Se@G NPs. The number of $\mathrm{RBC}$ in $1 \mathrm{~mm}^{3}$ of blood in mammals was reported $\sim 5 \times 10^{6}$ previously ${ }^{1}$ and the surface area of a single $\mathrm{RBC}$ was about $\sim 75 \mu \mathrm{m}^{2} .^{2}$ Thus, the total surface area of RBCs $\left(\mathrm{S}_{\mathrm{RBC}}\right)$ in $1000 \mu \mathrm{L}$ blood was:

$S_{R B C}=1000 \mu L \times 5 \times 10^{6} \times 75 \mu \mathrm{m}^{2}=0.375 \times 10^{12} \mu m^{2}$

The Ru-Se@G NPs were spherical with a diameter $(\mathrm{R})$ of $\sim 152 \mathrm{~nm}$ according to TEM data, the surface area of each Ru-Se@G NPs $\left(\mathrm{S}_{\mathrm{R}}\right)$ will be:

$$
S_{R}=4 \pi R^{2}=4 \pi\left(\frac{152 \mathrm{~nm}}{2} \times 10^{-3}\right)^{2} \approx 0.073 \mu m^{2}
$$

And the volume of each Ru-Se@G NPs $\left(V_{R}\right)$ will be:

$$
V_{R}=\frac{4}{3} \pi R^{3}=\frac{4}{3} \pi\left(\frac{152 \mathrm{~nm}}{2} \times 10^{-7}\right)^{3} \approx 1.84 \times 10^{-15} \mathrm{~cm}^{3} ;
$$

The mass density of gelatin $(\rho)$ is $1.37 \mathrm{~g} / \mathrm{cm}^{3}$, the mass of each Ru-Se@G NPs $\left(\mathrm{M}_{\mathrm{R}}\right)$ can be calculated as following:

$$
M_{R}=V_{R} \rho=1.84 \times 10^{-15} \mathrm{~cm}^{3} \times 1.37 \mathrm{~g} / \mathrm{cm}^{3} \approx 2.52 \times 10^{-15} \mathrm{~g}
$$

Therefore, the total surface area of Ru-Se@G NPs in stock solution $(10 \mathrm{mg} / \mathrm{mL}$, $1 \mathrm{~mL})$ was:

$$
S_{R T}=\frac{V C}{M_{R}} \times S_{R}=\frac{1 \mathrm{~mL} \times 10 \times 10^{-3} \mathrm{~g} / \mathrm{mL}}{2.52 \times 10^{-15} \mathrm{~g}} \times 0.073 \mu \mathrm{m}^{2}=0.290 \times 10^{12} \mu \mathrm{m}^{2}
$$




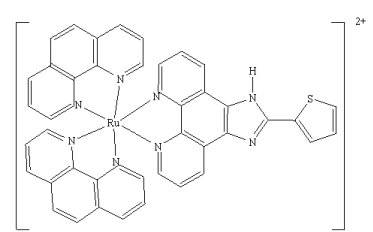

a. $\Delta-\left[\operatorname{Ru}(\text { phen })_{2}(\text { tip })\right]^{2+}$

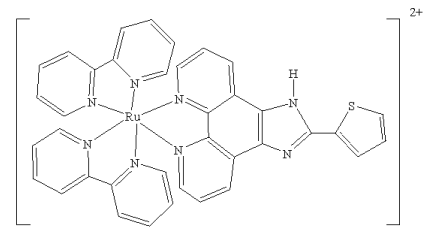

c. $\Delta-\left[R u(b p y)_{2}(\text { tip })\right]^{2+}$

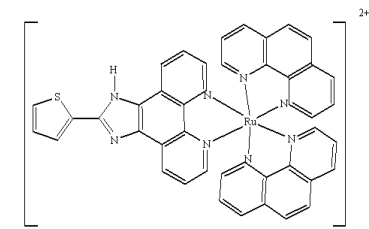

b.^-[Ru(phen) $)_{2}($ tip $\left.)\right]^{2+}$

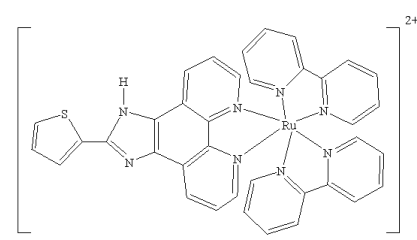

d. $\wedge-\left[R u(b p y)_{2}(\text { tip })\right]^{2+}$

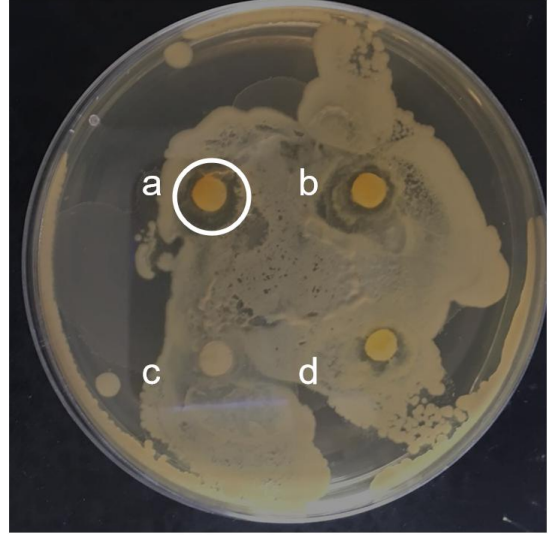

Figure S1. The structure of the tested ruthenium complexes, and the zone inhibition of a. $\Delta-\left[\operatorname{Ru}(\text { phen })_{2}(\text { tip })\right]^{2+}$, b. $\Lambda-\left[\operatorname{Ru}(\text { phen })_{2}(\text { tip })\right]^{2+}$, c. $\Delta-\left[\operatorname{Ru}(\text { bpy })_{2}(\text { tip })^{12+}\right.$ and d. $\Lambda$ $-\left[\mathrm{Ru}(\text { bpy })_{2}(\mathrm{tip})\right]^{2+}$, respectively. (a. $\Delta-\left[\mathrm{Ru}(\text { phen })_{2}(\text { tip })\right]^{2+}$ with the biggest inhibition zone, as marked with white circle, was chosen for further experiments. The disk diffusion test was repeated three times with a parallel format.)

Se NPs

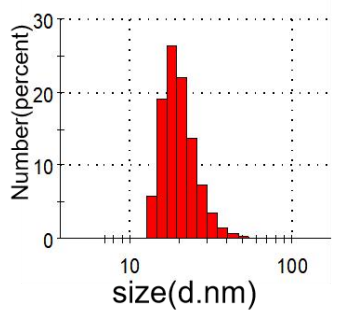

Ru-Se NPs

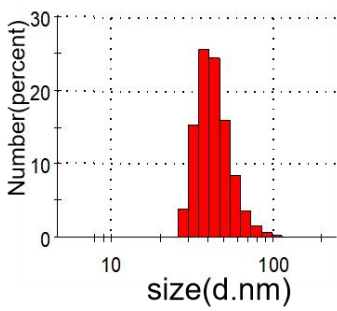

Ru-Se@G NPs Ru-Se@G NPs-RBCM
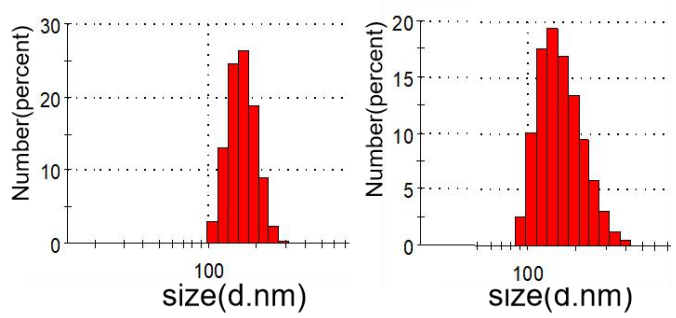

Figure S2. Diameter of Se NPs, Ru-Se NPs, Ru-Se@G NPs and Ru-Se@G NPs-RBCM during the process tested by DLS. 

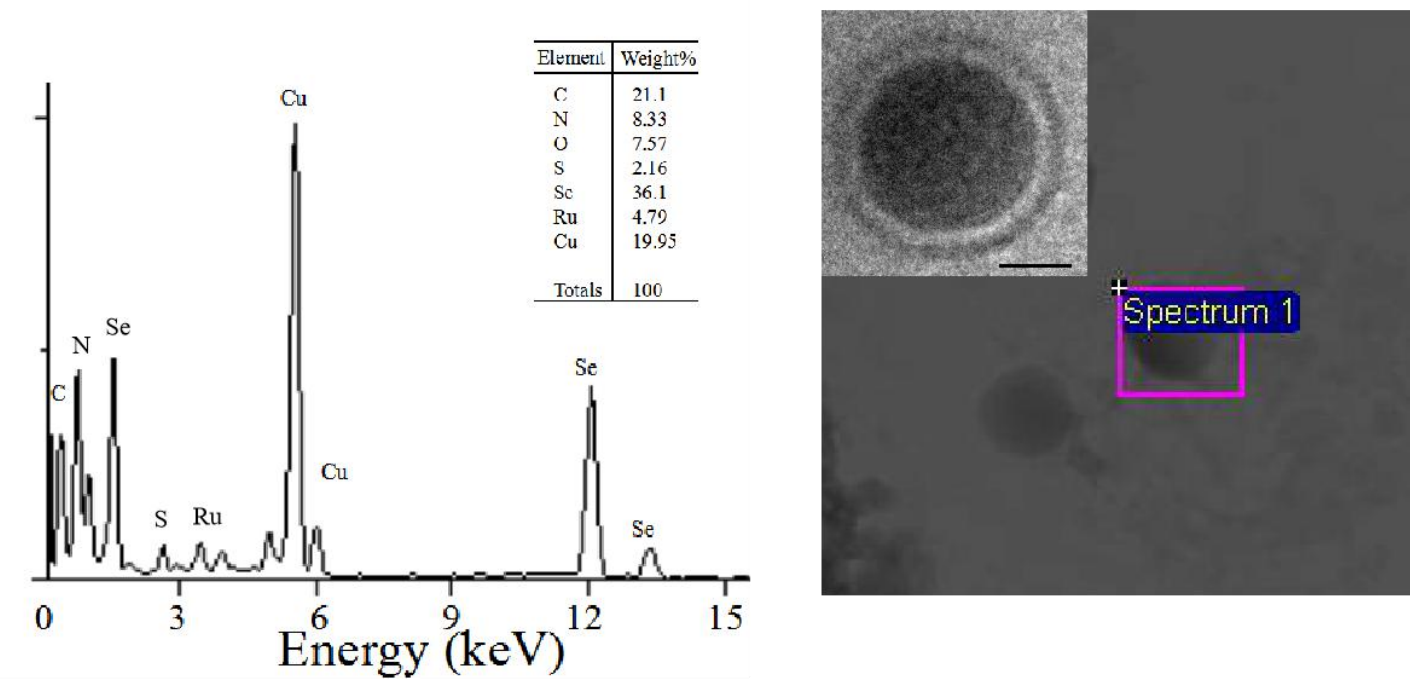

Figure S3. HRTEM-EDS spectrum of Ru-Se@G NPs-RBCM. Scale bar is $50 \mathrm{~nm}$.
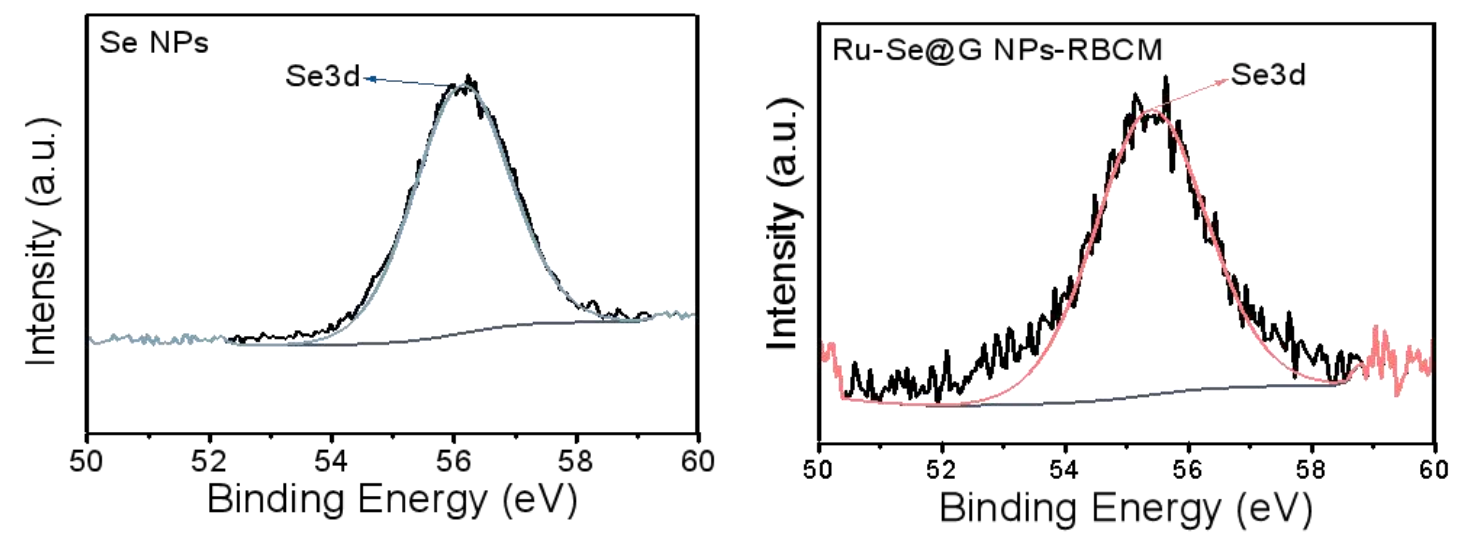

Figure S4. XPS spectra of Se NPs and Ru-Se@G NPS-RBCM. 


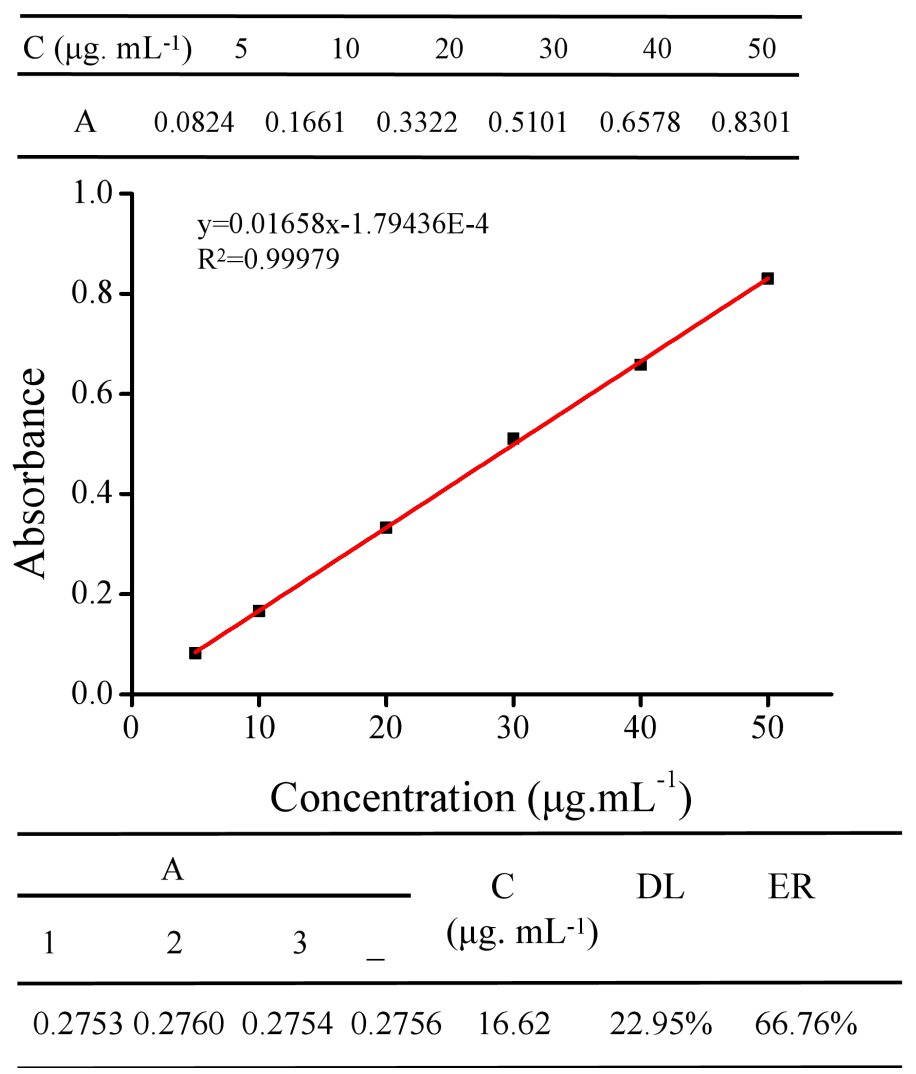

Figure S5. Standard curve plotting, drug loading and encapsulation rate assay of Ru-Se@G NPs nanosystem.
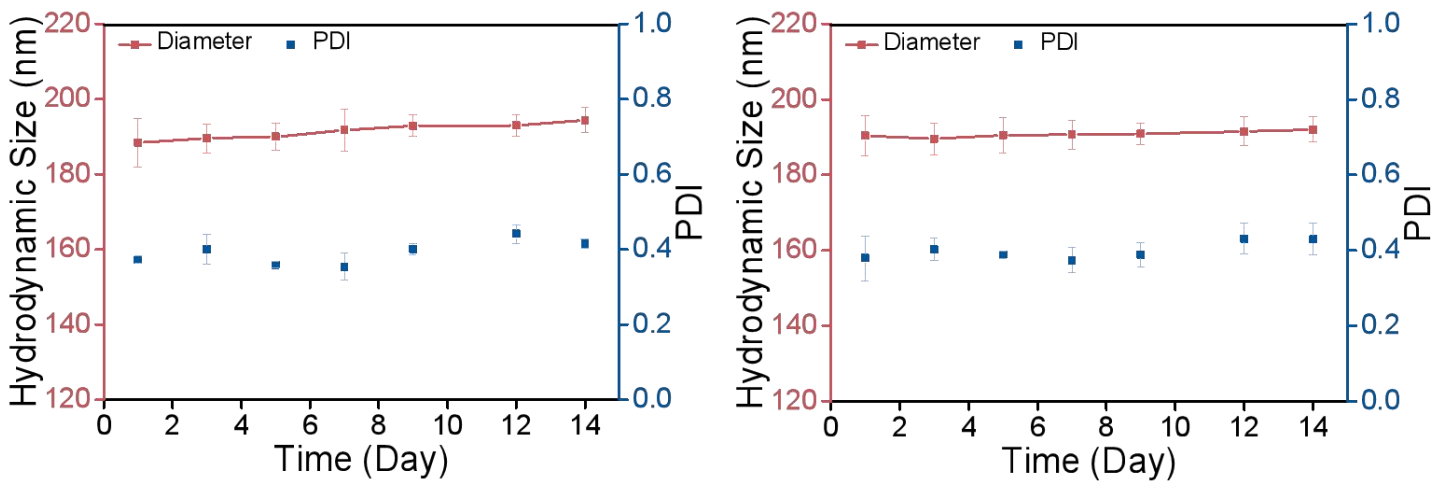

Figure S6. The size and PDI change of Ru-Se@G NPs-RBCM in water (left) and PBS buffer (right) at different storage time (1-14 days). 


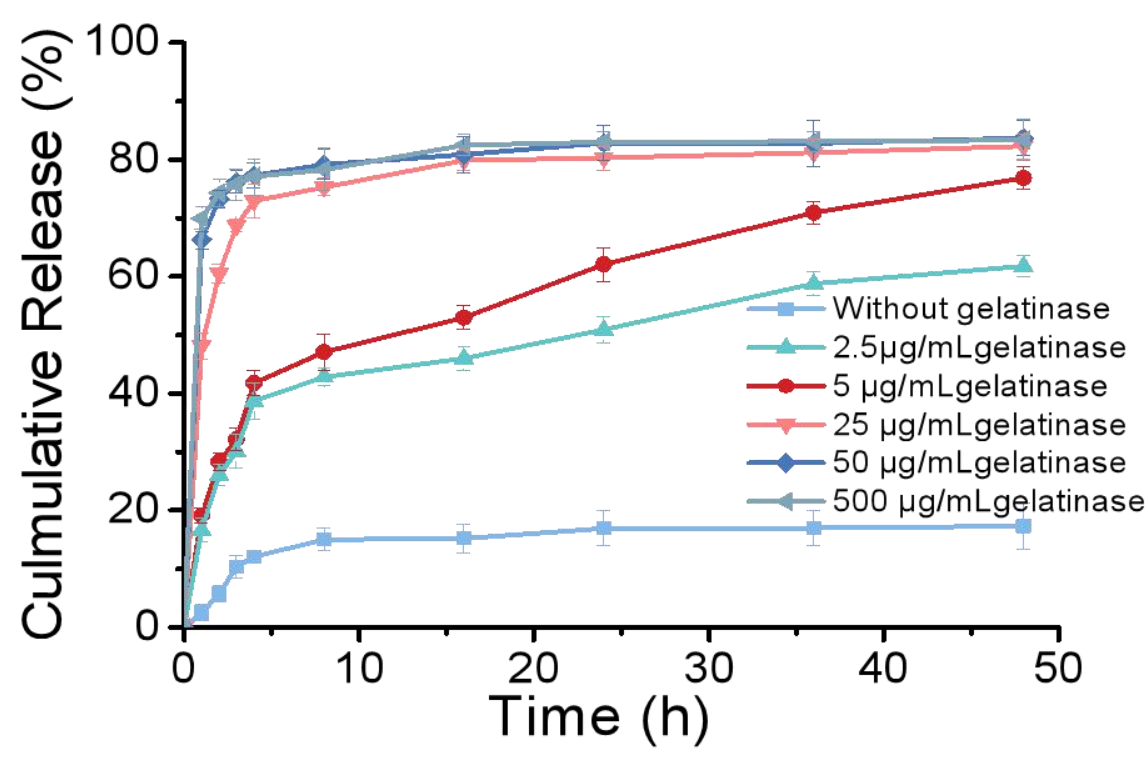

Figure S7. The representative time-dependent Ru-Se NPs release curves from Ru-Se@G NPs under different concentrations of gelatinase $(0,2.5,5,2550,500$ and $1000 \mu \mathrm{g} / \mathrm{mL}$ ) up to $48 \mathrm{~h}$.

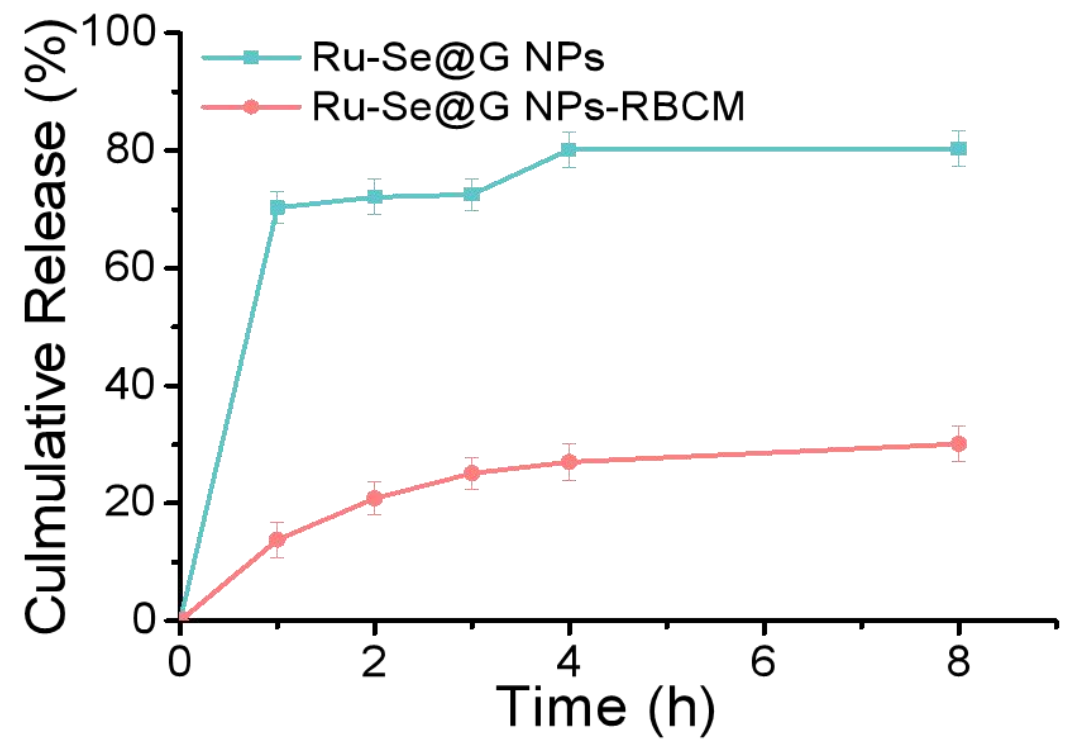

Figure S8. The time-dependent Ru-Se NPs release curves from Ru-Se@G NPs and Ru-Se@G NPs-RBCM under gelatinase $(0.5 \mu \mathrm{g} / \mathrm{mL})$ up to $8 \mathrm{~h}$. 

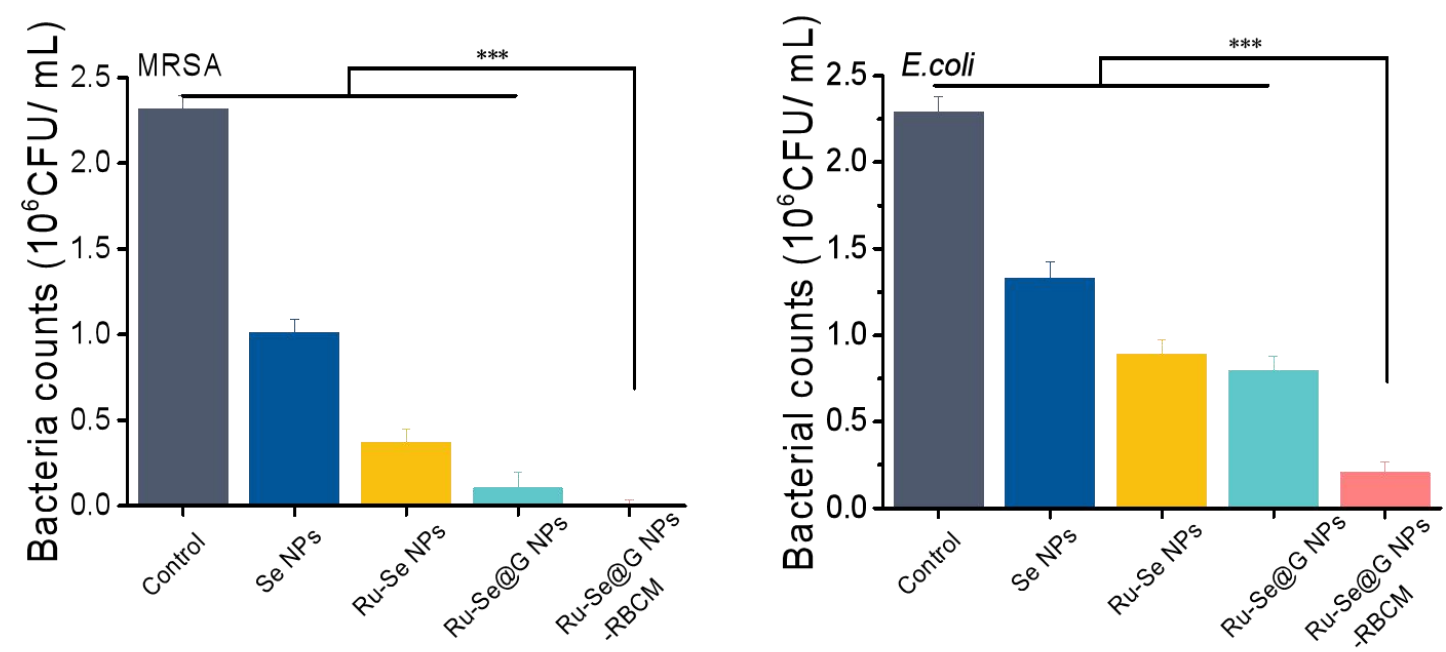

Figure S9. Change in MRSA and E.coli colony forming units $\left(10^{6} \mathrm{CFU} / \mathrm{mL}\right)$ after treatments with PBS, Se NPs, Ru-Se NPs, Ru-Se@G NPs and Ru-Se@G NPs-RBCM $(25 \mu \mathrm{g} / \mathrm{mL}) .(\mathrm{n}=3 ; * * * \mathrm{p}<0.001$.
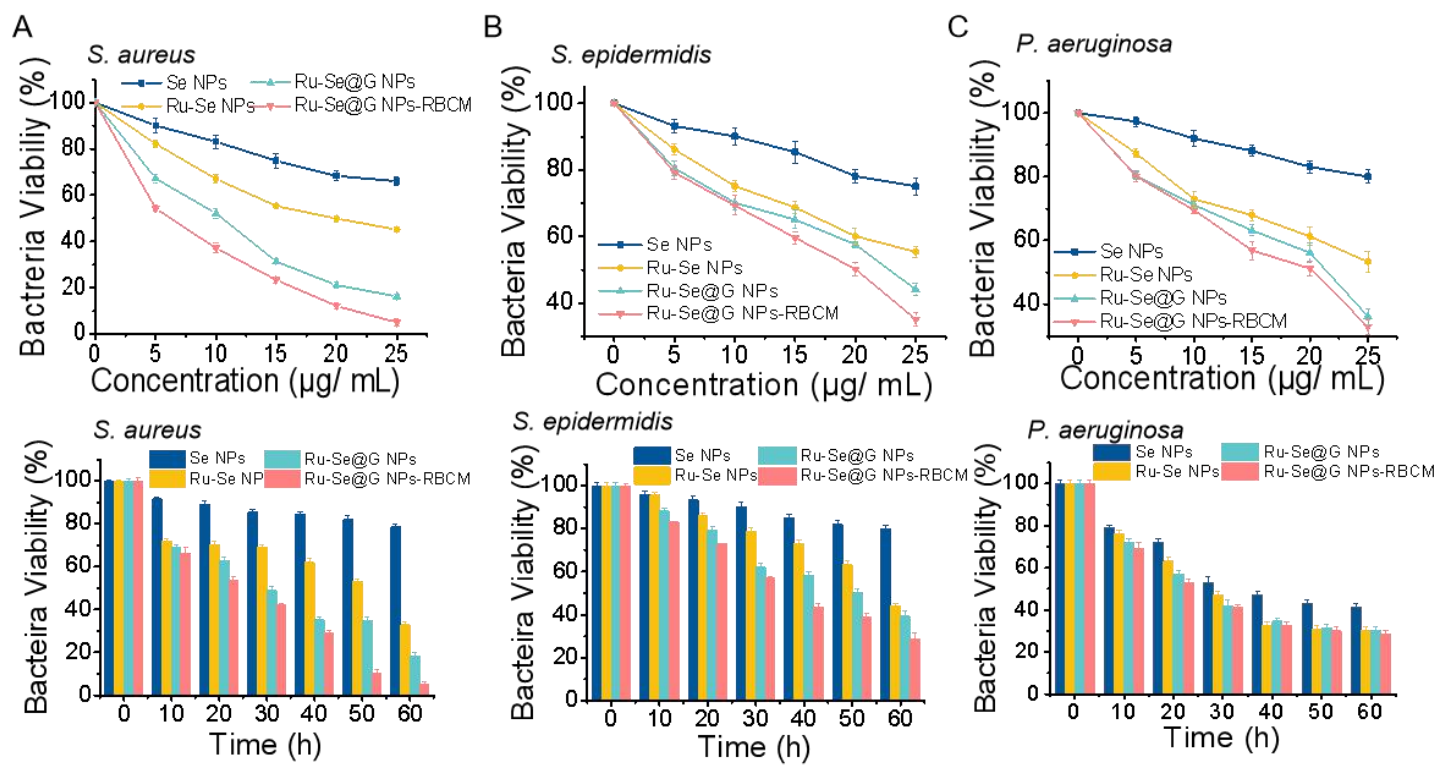

Figure S10. Detection of in vitro antibacterial activity. The survival rates of $S$. aureus (Gram positive, gelatinase positive), S. epidermidis (Gram positive, gelatinase negative) and $P$. aeruginosa (Gram negative, gelatinase positive) were detected for the same intervals with four samples (Se NPs, Ru-Se NPs, Ru-Se@G NPs and 
Ru-Se@G NPs-RBCM) at different concentrations, and under the same concentration $(25 \mu \mathrm{g} / \mathrm{mL})$ at predetermined intervals $(0-60 \mathrm{~min})$.

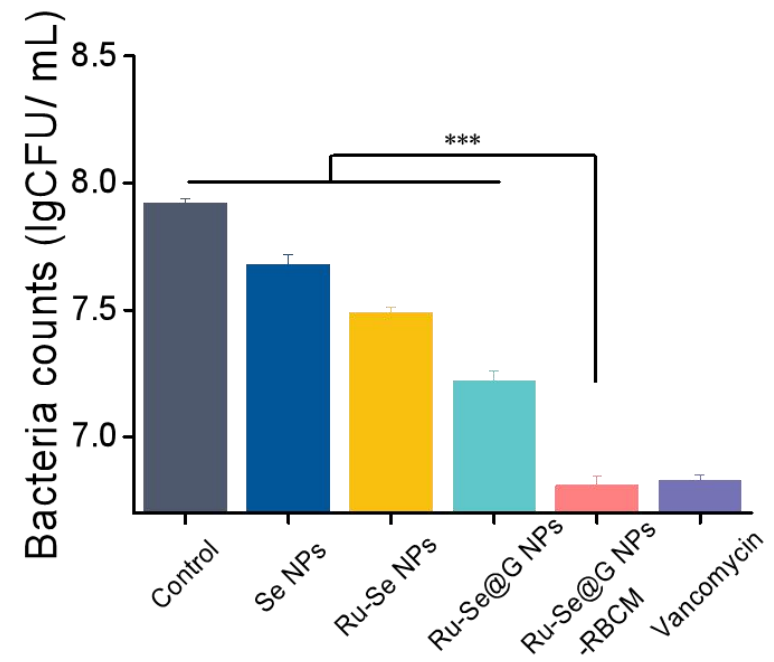

Figure S11. MRSA $(\operatorname{lgCFU} / \mathrm{mL})$ on knife injuries after treatments with PBS, Se NPs, Ru-Se NPs, Ru-Se@G NPs, Ru-Se@G NPs-RBCM and vancomycin. (n=3;***p < 0.001.)

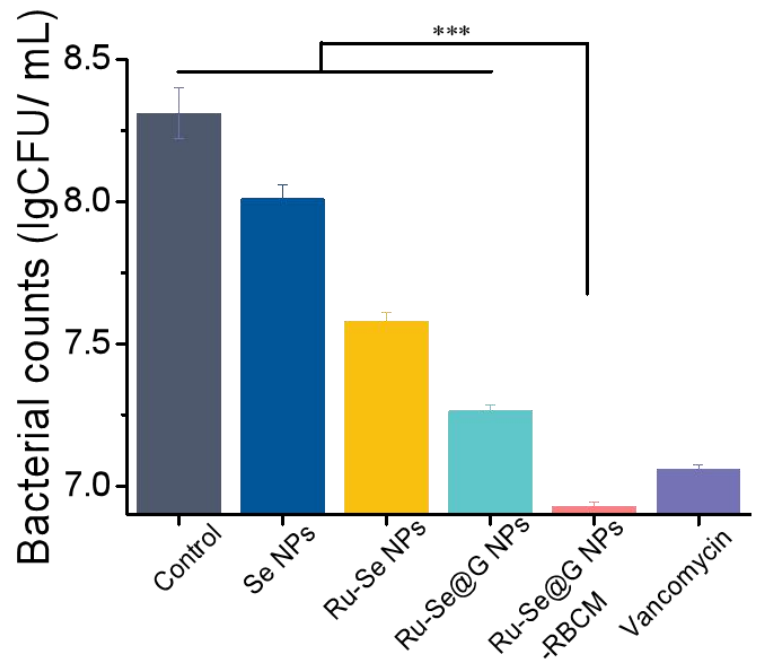

Figure S12. MRSA (lgCFU/ mL) on burn wounds after treatments with PBS, Se NPs, Ru-Se NPs, Ru-Se@G NPs, Ru-Se@G NPs-RBCM and vancomycin. (n=3;***p < 0.001.) 


\section{REFERENCE}

(1) A. Kostelecka-Myrcha, The Ratio of Amount of Haemoglobin to Total Surface Area of Erythrocytes in Mammals, Mammal Res 2002, 47, 209-220.

(2) R.E. Waugh, I. H. Sarelius, Effects of Lost Surface Area on Red Blood Cells and Red Blood Cell Survival in Mice, Am. J. Physiol. 1996, 271, 1847-1852. 